Published in "Journal of economics and finance", 2020, vol. 44, pp. 300-320, which should be cited to refer to this work.

DOI : 10.1007/s12197-019-09489-1

\title{
Is the Flow-Performance Relationship Really Convex? - The Impact of Data Treatment and Model Specification
}

\author{
This version: 7th September 2018
}

\begin{abstract}
This paper challenges the convexity of the flow-performance relationship, according to which investors strongly chase top-performing funds, while fund flows exhibit little to no sensitivity to past performance within the segment of poorly performing funds. Our results suggest that the flow-performance relationship is not convex, but rather linear. In contrast to prior studies, we use reported (i.e., exact) instead of approximated fund flow data, we trim (instead of winsorize) outliers, and we account for persistence in fund flows. We find that each factor contributes to serious biases. For example, investor reactions to poor performance only appear insignificant when outliers are winsorized instead of trimmed. And it is even more evident that fund investors flee poorly performing funds when the model incorporates lagged flows to account for fund flow persistence. Furthermore, our results provide evidence that the degree to which investors chase top-performing funds appears to be slightly upward biased if approximated fund flows are used. Our findings have important implications for the potential moral hazard of fund managers.
\end{abstract}

Key words: Mutual Funds, Fund Flows, Flow-Performance Relationship

JEL classification: G10, G11, G23 


\section{Introduction}

The mutual fund literature provides strong evidence that investors are highly sensitive to past fund performance. However, most studies also find that investors tend to disproportionately chase top-performing funds, while showing little to no fund flow sensitivity to poorly performing funds (Ippolito (1992), Sirri and Tufano (1998), Berk and Green (2004), Del Guercio and Tkac (2002), and Huang, Wei, and Yan (2007)). This phenomenon has been dubbed the convexity of the flow-performance relationship.

The flow-performance relationship has important implications for fund managers and asset management firms, because their fee income is usually tied to the amount of assets they have under management. Berk and Green (2004) even argue that the flow-performance relationship directly determines the degree to which fund volume is affected by past performance.

According to Chevalier and Ellison (1997), a convex flow-performance relationship leads to an agency conflict between fund managers and investors. This is because managers are incentivized to manipulate risk to increase the probability of high returns and high inflows, while investors want managers to maximize risk-adjusted returns. Consistent with this "moral hazard" effect, Brown, Harlow, and Starks (1996) empirically demonstrate that mid-year "loser" funds tend to increase fund volatility in the latter part of the annual assessment period. The authors also show that this effect increases over their sample period, during which industry growth and investor awareness of fund performance increased.

These studies have some commonalities. First, most had to approximate fund flows using fund size and returns, because reported fund flow data were not accessible. Approximated flows rely on the assumption that all flows occur at the end of the month, and that any dividends or distributions are reinvested (Chevalier and Ellison (1997)). Both assumptions are somewhat rigid, and raise the question of whether the usage of approximated fund flows may lead to biased regression results.

Since 1996, the Securities and Exchange Commission (SEC) has required funds to report their exact U.S. dollar fund flow. However, although exact fund flows are definitely preferable to approximated flows, both are highly sensitive to data 
entry issues, which may lead to strong outliers and thus biases in the econometric estimation.

This leads us to the issue of outlier treatment, which is the second potential problem these studies have in common. In order to avoid the regression results being biased by outliers in the sample, most papers winsorize their fund flows, i.e., they replace extreme outliers (positive or negative) with more plausible values, often the $1 \%$ to $99 \%$ values of the distribution. However, if the erroneousness is due to data entry problems, this approach may lead to serious biases. In this paper, we explain why extreme values should be trimmed instead (i.e., removed from the sample), and not winsorized.

Finally, the majority of past fund flow studies have neglected the potential persistence of fund flows in their empirical models. More recent studies argue that investors tend to react to information at somewhat different time intervals (Del Guercio and Tkac (2002), Cashman, Nardari, Deli, and Villupuram (2014)). Therefore, a control for persistence appears to be essential.

In this paper, we reexamine the flow-performance relationship of mutual funds by using reported instead of approximated flows and trimmed instead of winsorized extreme values. We also control for potential persistence of fund flows. Our empirical study is based on monthly data of U.S. mutual funds from 1999 through 2014.

Our key finding is that the winsorization of outliers leads to serious biases. Investors only appear insensitive to poor past performance when outliers are winsorized. When they are trimmed instead, we find evidence of a significant investor reaction to poor past performance. The reaction becomes even more obvious when the regression model controls for the persistence of fund flows. Interestingly, even with winsorized fund flows, we find some evidence of investor reaction to poor performance if we control for fund flow persistence. The use of lagged fund flows therefore appears to counteract potential biases from the inappropriate use of winsorization. Moreover, we find that the reaction of investors to superior performance is slightly overestimated if approximated instead of exact flows are used.

Our results challenge the convexity of the flow-performance relationship because we provide evidence that investors are sensitive to both poor and good past perfor- 
mance. Our findings have important implications for the potential moral hazard of fund managers. The lack of convexity implies that investors are withdrawing money for poor-performing funds. Contrary to previous research, fund managers and asset management companies should not be motivated to increase risk in order to benefit from potential strong performance. Our findings reveal that, ultimately, they would be penalized symmetrically for any underperformance that may accompany this risk-taking behavior.

Our paper contributes to a growing strand of literature that challenges the convexity of the flow-performance relationship. Using market share-adjusted fund flows, Spiegel and Zhang (2013) find evidence that investors do flee poor performance. Furthermore, Clifford, Jordan, and Riley (2014) document a linear flow-performance relationship for the subsample of the largest mutual funds. Interestingly, both findings rely on modifications of the original research setting. The authors of both papers highlight that their studies should not be taken as a critique of established articles for that reason. It is also important to note that both papers document evidence against a linear flow-performance relationship by focusing on an alternate setting compared to classical studies of the flow performance relationship. Our article is the first to demonstrate a linear flow-performance relationship in a classical setting.

The remainder of this paper is organized as follows. Section 2 describes our data and variables and provides some descriptive statistics. Section 3 provides the regression results for the flow-performance relationship using our suggested approach. Section 4 concludes.

\section{Base Model, Data Sources, and Sample Descrip- tion}

\subsection{Base Model}

The flow-performance relationship is generally estimated by the following piecewise linear regression model (see, for example, Sirri and Tufano (1998)). The flow (flow $i, t)$ of fund $i$ at time $t$ is modeled as a function of the fund's past return $\left(R_{i, t-1}\right)$, logarithm 
of its total net assets $\left(\right.$ lTNA $\left._{i, t-1}\right)$, riskiness (riskiness $\left.{ }_{i, t-1}\right)$, expenses (Expenses $\left.{ }_{i, t-1}\right)$, and total fund flows into all funds with the same investment objective (objective flow $w_{i, t}$ ):

$$
\begin{aligned}
& \text { flow }_{i, t}=f\left(l T N A_{i, t-1}, g\left(R_{i, t-1}\right), \text { Riskiness }_{i, t-1},\right. \\
& \text { Expenses }_{i, t-1} \text {, objective } \text { flow }_{i, t} \text { ) }
\end{aligned}
$$

In particular, we use a fund's relative performance to explain subsequent fund flows. In each time period, all funds within the same investment objective are ranked according to their performance. This variable is called $\operatorname{Rank}_{i, t}$, and ranges from 0 to 1 . The performance is then separated into three performance percentiles, which allows us to model a potential non-linear relationship between fund flows and past performance. The bottom quantile is specified as:

$$
\text { low } \text { return }_{i, t-1}=\min \left(0.2, \operatorname{Rank}_{i, t-1}\right)
$$

The middle quantile is defined as:

$$
\operatorname{midreturn}_{i, t-1}=\min \left(0.6, \operatorname{Rank}_{i, t-1}-\text { low return }_{i, t-1}\right)
$$

The top quantile is defined as:

$$
\begin{gathered}
\text { high return } n_{i, t-1}=\min \left(0.2, \operatorname{Rank}_{i, t-1}-\operatorname{mid} \text { return } n_{i, t-1}-\right. \\
\text { low return } \left.n_{i, t-1}\right)
\end{gathered}
$$

We use rolling twelve-month returns as a measure of fund performance $\left(R_{i, t}\right)$. This information is generally available to fund investors through the databases of leading mutual fund data providers.

Additionally, we control for fund fees $\left(\right.$ Expenses $\left._{i, t}\right)$, because they have a direct impact on fund investors' net performance. As per Sirri and Tufano (1998), we calculate the total fees an average investor would incur to hold a fund by adding one-seventh of the front load to the expense ratio. The front load is divided by seven because the average holding time of a fund investor is seven years.

Next, because investor behavior is likely to differ according to investment objec- 
tive, we include the variable (objective flow $w_{i, t}$ ) to control for sector-level fund flows. This measure is defined as the sum of all flows within a specific investment objective, and is calculated on the basis of the Morningstar variable prospectus objective. Because we use two different flow measures in this study, we define the respective objective flows accordingly.

The variable $\left(l T N A_{i, t}\right)$ is defined as the natural logarithm of total net assets. It is essential to control for TNA because the relative impact of an equal dollar flow is higher for a smaller fund than for a larger one.

Finally, we account for fund riskiness, (Riskiness ${ }_{i, t}$ ), by using the volatility of fund returns over the past twelve months as a further control variable.

\subsection{Data Sources and Sample Description}

Our sample period covers monthly mutual fund data from January 1999 through December 2014. The dataset comes from the Morningstar Direct investment research database. Our sample includes monthly fund-level data on total net assets, reported flows, and fund returns. The net expense ratio and the maximum front load are updated annually. We also control for indicator variables such as the fund's prospectus investment objective, or information on mergers.

Mutual funds typically offer several share classes for the same investment portfolio. We use the fund ID provided by Morningstar in order to aggregate share class-level data at the mutual fund level. To prevent survivorship bias, we include active as well as non-surviving funds.

We use the Morningstar variable prospectus objective in order to determine a fund's investment objective. We focus here primarily on equity mutual funds from the following investment objectives: growth and income, aggressive growth, growth, equity-income, income, and small company. 


\section{Reported versus Approximated Flows, Outlier Treatment, and Model Specification}

\subsection{Reported versus Approximated Flows}

The SEC has only required mutual funds to report monthly net flows since 1996. For this reason, early studies on the flow-performance relationship approximated fund flows according to the following formula (e.g., Sirri and Tufano (1998)):

$$
\text { flow } \operatorname{approx}_{i, t}=\frac{T N A_{i, t}-T N A_{i, t-1}\left(1+R_{i, t}\right)}{T N A_{i, t-1}}
$$

The accuracy of this commonly used fund flow approximation relies on the assumption that all dividends are reinvested and that all fund flows occur at the end of a respective month. As mentioned earlier, however, there are two concerns with these assumptions. First, because we are assuming fund flows occur at the end of the period, approximated flows neglect the fact that intra-period net flows are also affected by funds' intra-period returns. This factor can lead to dramatic differences between exact and approximated fund flows during months with high absolute flows and/or high absolute returns. Second, the assumption that dividends are completely reinvested may be too rigid. Nevertheless, Clifford, Fulkerson, Jordan, and Waldman (2013) report that the correlation between reported and approximated flows is $99.6 \%$, which is quite high. They interpret this as an indicator of the accuracy of previously used fund flow approximations.

Because funds have been required to report their real U.S. dollar flows to the SEC since 1996, this enables a direct comparison between approximated and reported fund flows. The relative (\%) reported flows ${ }^{1}$ are calculated as follows:

$$
\operatorname{flow}_{i, t}=\frac{\text { flow }_{i, t}}{T N A_{i, t-1}}
$$

Figure 1 shows the mean differences between aggregated and reported fund flows over our sample period. In each month, we subtract the mean of all approximated fund

1 We control for fund mergers by calculating the sum of the TNA of all merged funds that flowed into an acquiring fund, and then adjust the respective fund flows accordingly. 
flows from the mean of all reported mutual fund flows. The graph suggests there are substantial differences that also appear to be subject to seasonality. For example, the flow difference tends to be largest in December, when most funds pay their dividends.

We note that econometric analyses are vulnerable to the omitted variable bias. This is the case if the model leaves out an important variable that is correlated with the dependent variable and one or more of the explanatory variables. Here, we can expect the regression results to be unbiased only if there is no correlation between flow differences, which are driven by dividends, and the other variables of the regression model. Table 1 shows there is a significant correlation between flow differences and fund flows. The flow difference is correlated with returns. Additionally, we find a relationship between dividends and returns. The correlations between the flow difference and the fund flows, as well as those between dividends and the control variables, are remarkably high. The correlation coefficients between flow differences and the control variables are rather moderate.

Together, the correlations and the mean flow differences suggest that using approximated instead of reported flow data may lead to biased regression results. Thus, we formulate our first hypothesis as follows:

Hypothesis 1: The use of approximated instead of exact fund flows leads to biased regression results for the flow-performance relationship.

\subsection{Trimming versus Winsorizing of Outliers}

The statistical literature cites various reasons that observations may take on extreme values. In social statistics, for example, outliers may occur when an older person overstates his age. This occurs particularly in rural or underdeveloped regions, where birth documents may be non-existent. In this case, it is appropriate to replace extremely positive outliers by more plausible, yet also high, outliers. In other words, the value should be winsorized in order to avoid having the overly high outlier drive the sample (Ghosh and Vogt (2012)). Winsorization replaces any positive (negative)

extreme values with more moderate maximum (minimum) values, for example, the ninety-ninth (first) percentile. 
Data entry issues, which may occur through, e.g., typing errors, are another potential reason for erroneous outliers. Here, a seemingly very high number could be a very small number in reality. In this case, winsorization could lead to biased regression results because the explanatory variables should predict a very low value instead of a very high one. Thus, trimming (excluding outliers completely from an analysis when they exceed (or fall below) a certain threshold) would be more appropriate. We conduct a plausibility check regarding the most extreme outliers in our sample, and find that the vast majority appear to be due to data entry problems. Thus, we argue that, in the mutual fund literature, trimming should clearly be preferred over winsorization with respect to fund flows.

There is no consensus in the mutual fund flow literature on how to treat outliers, however. Some studies, such as, e.g., Elton, Gruber, and Blake (1996), Clifford et al. (2014), Casavecchia (2016), and Ferreira, Keswani, Miguel, and Ramos (2012), winsorize them, while others trim outlying values (e.g., Huang et al. (2007), Spiegel and Zhang (2013) and Cashman et al. (2014)). In contrast, (Chevalier and Ellison (1997) and Sirri and Tufano (1998)) aim to ensure high data quality in their sample by cross-checking their data with other databases, while leaving outliers unchanged.

In this study, we examine how the estimated flow-performance relationship differs depending on whether outliers are winsorized or trimmed. We trim and winsorize both reported and approximated fund flows at the 1\% and 99\% percentiles.

In the mutual fund literature, winsorizing $1 \%$ of the most extreme values is the most commonly used approach (see, for example, Clifford et al. (2013), Elton et al. (1996), Casavecchia (2016), and Ferreira et al. (2012)). Clifford et al. (2014) winsorize at the $2.5 \%$ percentiles. On the other hand, Huang et al. (2007) trim at the 2.5\% percentiles and Spiegel and Zhang (2013) at the 5\% percentiles while Cashman et al. (2014) eliminate observations with inflows below $-12 \%$ and outflows above $50 \%$.

Table 2 provides the summary statistics for our flow measures and some control variables for the entire sample period, as well as for December 2000, December 2007, and December $2014 .^{2}$ The numbers reveal that trimmed flows generally have a substantially lower mean than winsorized flows. In untabulated results, we find that

2 The variable riskiness is based on the fund returns of the past twelve months. Therefore, the first analyzable observation is January 2000. 
about half the $1 \%$ highest outflows (those which we define as outliers) are actually associated with positive returns, and about one-quarter with extraordinary returns. It is thus doubtful that the highest outflows are associated with high returns. This supports our argument that outliers tend to be driven by data entry issues, and hence should be trimmed, not winsorized.

Following Sirri and Tufano (1998), we also provide a graphical representation of the flow-performance relationship. For each investment objective, and for each month, all funds are ranked according to their performance over the previous twelve months, and then split into twenty quantiles. We calculate the average net flow (\%) into each of the twenty performance quintiles in the following month.

Figure 2 illustrates the relationship between the funds' money growth rates and past performance. The upper panel (A) shows the resulting flow-performance relationship for different trimming thresholds. It is obvious that lower thresholds lead to more convex flow-performance relationships. In contrast, higher trimming quantiles lead to more linear flow-performance relationships.

The lower panel (B) illustrates the flow-performance relationship using winsorized data, treated at the same thresholds as in (A). As with the case of trimming, we find a less convex flow-performance relationship for higher winsorizing thresholds. Yet the relationship is more convex than (B), even when higher thresholds are applied. The comparison of the $1 \%$ winsorized and trimmed flow-performance graphs in Figure 3 reveals that the flow-performance relationship is less convex (or more linear) when the outliers are trimmed instead of winsorized. In particular, the lowest performance quintiles are associated with smaller fund flows.

We suspect that winsorizing leads to retaining attenuated versions of incorrect values. The inclusion of these values influences the shape of the flow-performance relationship and may affect empirical conclusions. Thus, we formulate our hypothesis regarding the effect of outliers on the bottom performance quantile as follows:

Hypothesis 2: Winsorizing instead of trimming outliers hides investor sensitivity to poor performance. 


\subsection{Accounting for Fund Flow Persistence}

More recent studies have emphasized the importance of controlling for the persistence of fund flows when examining the flow-performance relationship (see, e.g., Del Guercio and Tkac (2002), Johnson (2007), and Cashman et al. (2014)). Cashman et al. (2014) argue that fund investors react to performance changes rather sluggishly. In other words, they react to new information in a learning process over different time intervals. Furthermore, the authors argue that using twelve lags prevents any bias due to potential seasonal patterns in the monthly fund flows.

While these studies do not focus primarily on the shape of the flow-performance relationship, we argue that fund flow persistence is likely to be an important factor in our setting because its neglect may lead to biased regression results. Therefore, we formulate our third hypothesis as follows:

Hypothesis 3: Neglecting persistence leads to a biased flow-performance relationship.

To examine the impact of fund flow persistence on the shape of the flow-performance relationship, we estimate an alternative model that includes twelve lags of monthly fund flows in addition to the initial base specification:

$$
\begin{gathered}
\text { flow }_{i, t}=f\left(\sum_{j=1}^{12} \text { flow }_{i, t-j}, l T N A_{i, t-1}, g\left(R_{i, t-1}\right), \text { Riskiness }_{i, t-1},\right. \\
\text { Expenses } \left._{i, t-1}, \text { objective flow }_{i, t}\right)
\end{gathered}
$$

\section{Regression Results}

Table 3 contains the regression results for the flow-performance relationship using diverse approaches. We test three hypotheses, each of which refers to an alternative way to estimate the flow-performance relationship relative to the standard approach. In particular, we vary: 1) reported versus approximated flows, 2) trimmed versus winsorized outliers, and 3) controlling for versus neglecting fund flow persistence. We also test whether the results for reported versus approximated fund flows differ depending on whether the data are trimmed or winsorized, and we test whether 
these four specifications are affected by whether we control for persistence. In total, this results in eight different specifications. The respective regression results are in Table 3. All regressions are estimated using the Fama-MacBeth procedure (Fama and MacBeth (1973)).

First, we replicate the standard approach to estimating the flow-performance relationship by using approximated fund flow data, winsorized at the first and ninetyninth percentiles. The respective regression results are in column (i) of Table 3, and confirm the convexity of the flow-performance relationship. While investors are highly sensitive to medium and high levels of past performance, the reaction of fund flows within the low performance quantile is not statistically different from zero. The adjusted R-squared is rather low, at only 5.8\%, and the control variables all have the expected sign, except for the impact of riskiness, which appears to be positively correlated with fund flows.

Column (ii) contains the regression results for the same specification. However, in this case, we use the fund flows reported to the SEC, instead of the approximated version. The regression results are overall very similar to those in column (i). We still find no evidence of investor reaction in the low performance fractile. Thus, the use of approximated instead of reported fund flows does not appear to have an impact on the shape of the flow-performance relationship (Hypothesis 1). Nevertheless, there are some minor improvements that suggest reported fund flow data should be preferred when available. For example, the adjusted R-squared increases from 5.8\% to 6.3\%, and the impact of fund return volatility is no longer significant, which makes sense if we assume that most investors are not risk-tolerant.

Columns (iii) and (iv) replicate the specifications in columns (i) and (ii), this time by trimming instead of winsorizing the outliers. Remarkably, by using trimmed data, the reaction to poor performance becomes significant for both specifications. The sensitivity of fund flows to poor performance is even stronger than the reaction to medium performance levels. The top performance reaction parameter remains the one with the highest significance.

Note that these results are consistent with Hypothesis 2: Investors appear sensitive to poor performance only when outliers are eliminated instead of winsorized. In 
other words, the (unjustified) winsorization of outliers masks investor sensitivity to poor performance, which may lead to incorrect conclusions. The R-squared of the specifications in columns (iii) and (iv) are also considerably higher than in the models using winsorized data.

Columns (v) to (viii) replicate the analysis of the first four columns, this time controlling for fund flow persistence. Interestingly, we observe that the reaction in the bottom performance quantile becomes significant for both outlier treatment approaches. This suggests that controlling for fund flow persistence may heal the shortcomings of winsorization to some extent. However, the sensitivity is still considerably more pronounced when outliers are trimmed and not winsorized (Approach 1). Overall, the results are consistent with Hypothesis 3: The neglect of fund flow persistence masks investor sensitivity to poor performance.

Again, it does not seem to make a big difference whether reported or exact flows are used. However, the relationship in the low-performance area is about $50 \%$ stronger for the trimmed dataset compared to the winsorized dataset. There is also some evidence that the use of approximated fund flows leads to a slight overestimation of investors' reactions to superior performance. In the trimmed dataset, we can reject the hypothesis that the high performance reaction parameters are equal, independent of the fund flow definition, with a p-value of $2 \%$. Therefore, we also find some evidence for Hypothesis 1.

Comparing the results for both datasets (trimmed versus winsorized), we can reject the hypothesis that the low-performance reaction parameters are equal. This result is once more in line with Hypothesis 2, suggesting that winsorizing leads to a biased estimate for the bottom quantile. Compared to the middle quantile, the low-performance parameter is significantly different and several times higher for both approaches. Investors' reactions to superior performance remain extraordinarily high, and deviate significantly from the other performance reaction parameters. However, we identify a dramatic reduction in parameter magnitude that is reduced by half when we control for fund flow persistence. This result supports Hypothesis 3, because the flow-performance relationship shifts in a meaningful way.

Additional evidence in favor of our preferred specification (model viii) is provided 
by the expected negative sign of the impact of the control variable riskiness, and by the R-squared, which is substantially higher than in all other regression specifications.

In summary, our findings reveal that the flow-performance relationship is highly sensitive to the way outliers are treated and to controlling for persistence. In contrast, we find that using approximated flows only slightly overestimates investors' reactions to strong performance. Hence, the way data are cleaned before being incorporated into an analysis, and controlling for persistence, are of major importance.

Winsorizing (instead of trimming) fund flows leads to a serious downward bias for the low-performance parameter, and, depending on the model specification, even to insignificance. We suspect that the bias for the winsorized dataset is due to data entry issues.

Controlling for persistence may heal the shortcomings of using winsorized data to some extent. We interpret the shift in the shape of the flow-performance relationship for the winsorized dataset after controlling for persistence as follows: The attenuated versions of outliers that are retained in the considered sample are smoothed out. Therefore, the outliers of the most extreme outflows are a purely random process. A moderate or even high return that is followed by an erroneous extreme outflow in the following period biases the short-run influence of past returns to fund flows. They have no influence on the immediate subsequent month. Thus, these outliers show an immediate effect that has no long-run influence on the flow-performance relationship. Consequently, after controlling for persistence, their influence weakens, and the poor performance relationship transforms into a significantly positive parameter.

In summary, our research suggests investors do punish poor performance across the broad spectrum of mutual funds and not only in modified cases of the original research question as in the studies of Spiegel and Zhang (2013) and Clifford et al. (2014). Importantly, and in contrast to the prevailing school of thought, our research findings do not imply that there is a potential misalignment of incentives between fund managers and investors. As the flow-performance relationship is linear, fund managers do not have an incentive to take excessive risk in order to benefit from asymmetric reactions of investors. 


\section{Conclusion}

This study readdresses the well-established convexity of the flow-performance relationship by using a new combination of state-of-the-art methods and new data. In particular, we use reported instead of approximated fund flows, we trim instead of winsorize outliers, and we follow the recent literature by controlling for fund flow persistence.

Through the combination of these approaches, three major findings emerge. First, we find substantial differences between approximated and reported fund flows. The neglected part of approximated fund flows exhibits seasonal patterns. The differences are particularly pronounced during December, when dividends are paid. Importantly, we find significant correlations between the neglected part of the fund flow approximations and the commonly incorporated variables used to model fund flows. Because common econometric analyses rely on the assumption that none of the neglected factors are correlated with the explanatory variables, this may lead to biased estimates. We find evidence that investors' reactions to strong performance is slightly overestimated in the models that use approximated instead of exact fund flows, as reported to the SEC. Therefore, we recommend using reported fund flows when available.

Second, we find that the winsorization of outliers leads to an insignificant flowperformance relationship in the low-performance quantile. In contrast, when outliers are trimmed, the coefficient on fund flow sensitivity with respect to poor performance becomes positive and significant. Surprisingly, the reaction is significantly stronger than even medium performance levels. We suspect that winsorizing leads to the inclusion of incorrect values, and may be causing biased estimates.

Third, we find that controlling for persistence also substantially impacts the shape of the flow-performance relationship, because the reaction of fund flows to poor performance becomes even stronger. Overall, we find that mutual fund investors strongly react to both strong and poor past performance. This is consistent with a linear, rather than a convex, flow-performance relationship.

Our findings have important implications for the potential moral hazard of fund managers. Previous studies, such as Chevalier and Ellison (1997), Brown et al. (1996), and Sirri and Tufano (1998), suggest fund managers are incentivized to take on risk 
in order to increase fund flows. They argue that the reward for extraordinarily high returns is very high, while the penalty for extraordinarily low performance is more modest. However, those studies incorporated outliers, neglected fund flow persistence, and used approximated fund flows.

Our approach sheds a new light on the debate regarding potentially perverse incentives for fund managers and the asset management industry. Poor performance is associated with lower fund flows, and hence does have an impact on assets under management and fee income. Managers should therefore avoid excessive risk-taking. Ultimately, we find that the rewards for high performance are much more comparable to the penalties for low performance than prior studies have suggested. 


\section{References}

Berk, J. B. and R. C. Green (2004). Mutual fund flows and performance in rational markets. Journal of Political Economy 112(6), 1269-1295.

Brown, K. C., W. V. Harlow, and L. T. Starks (1996). Of tournaments and temptations: An analysis of managerial incentives in the mutual fund industry. The Journal of Finance 51(1), 85-110.

Casavecchia, L. (2016). Fund managers' herding and the sensitivity of fund flows to past performance. International Review of Financial Analysis 47, 205-221.

Cashman, G. D., F. Nardari, D. N. Deli, and S. V. Villupuram (2014). Investor behavior in the mutual fund industry: evidence from gross flows. Journal of Economics and Finance 38(4), 541-567.

Chevalier, J. and G. Ellison (1997). Risk taking by mutual funds as a response to incentives. Journal of Political Economy 105(6), 1167-1200.

Clifford, C. P., J. A. Fulkerson, B. D. Jordan, and S. Waldman (2013). Risk and fund flows. Unpublished Working Paper.

Clifford, C. P., B. D. Jordan, and T. B. Riley (2014). Average funds versus average dollars: Implications for mutual fund research. Journal of Empirical Finance 28, 249-260.

Del Guercio, D. and P. A. Tkac (2002). The determinants of the flow of funds of managed portfolios: Mutual funds vs. pension funds. Journal of Financial and Quantitative Analysis 37(4), 523-557.

Elton, E. J., M. J. Gruber, and C. R. Blake (1996). Survivor bias and mutual fund performance. The Review of Financial Studies 9(4), 1097-1120.

Fama, E. F. and J. D. MacBeth (1973). Risk, return, and equilibrium: Empirical tests. Journal of Political Economy 81(3), 607-636. 
Ferreira, M. A., A. Keswani, A. F. Miguel, and S. B. Ramos (2012). The flowperformance relationship around the world. Journal of Banking \& Finance 36(6), $1759-1780$.

Ghosh, D. and A. Vogt (2012). Outliers: An evaluation of methodologies. In Joint Statistical Meetings, pp. 3455-3460. American Statistical Association San Diego, CA.

Huang, J., K. D. Wei, and H. Yan (2007). Participation costs and the sensitivity of fund flows to past performance. The Journal of Finance 62(3), 1273-1311.

Ippolito, R. A. (1992). Consumer reaction to measures of poor quality: Evidence from the mutual fund industry. The Journal of Law and Economics 35(1), 45-70.

Johnson, W. T. (2007). Who monitors the mutual fund manager, new or old shareholders. Unpublished Working Paper.

Sirri, E. R. and P. Tufano (1998). Costly search and mutual fund flows. Journal of Finance 53(5), 1589-1622.

Spiegel, M. and H. Zhang (2013). Mutual fund risk and market share-adjusted fund flows. Journal of Financial Economics 108(2), 506-528. 


\section{Appendix A: Figures}

Figure 1: Fund Flow Difference over Time

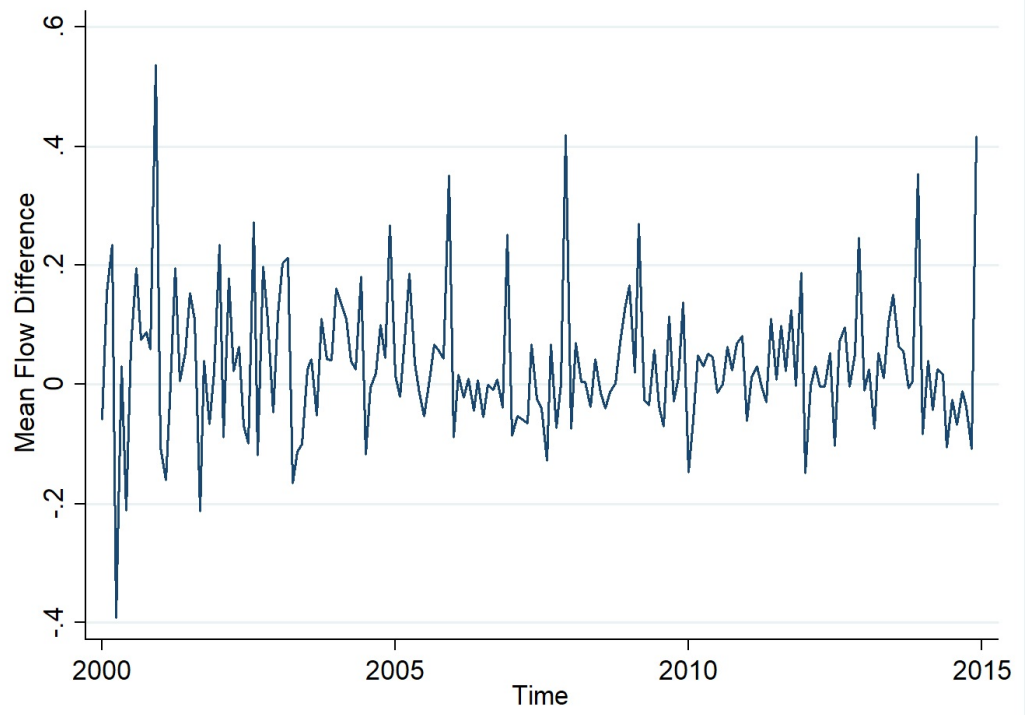

We calculate the mean reported and mean approximated fund flows for each period from 1999 to 2014. Mean flow difference is defined as the difference between mean reported and mean approximated fund flows. Therefore, reported fund flow is given by the ratio of fund flows and total net assets, defined as Flowt $/ T N A_{t-1}$, where Flowt is the fund flow reported to the SEC at time textitt, and $T N A_{t}$ is the fund's total net assets in period textitt. The approximated fund flow is given by (TNA $A_{t^{-}}$ $\left.T N A_{t-1}\left(1+R_{i, t-1}\right)\right) / T N A_{t-1}$, where $R_{i, t}$ is the fund's monthly return at time textitt. We choose a trimming quantile of $1 \%$ in order to cut outlying fund flows from the sample. 
Figure 2: Flow-Performance Relationship Using Different Outlier Treatment Methods

A: Trimmed Data
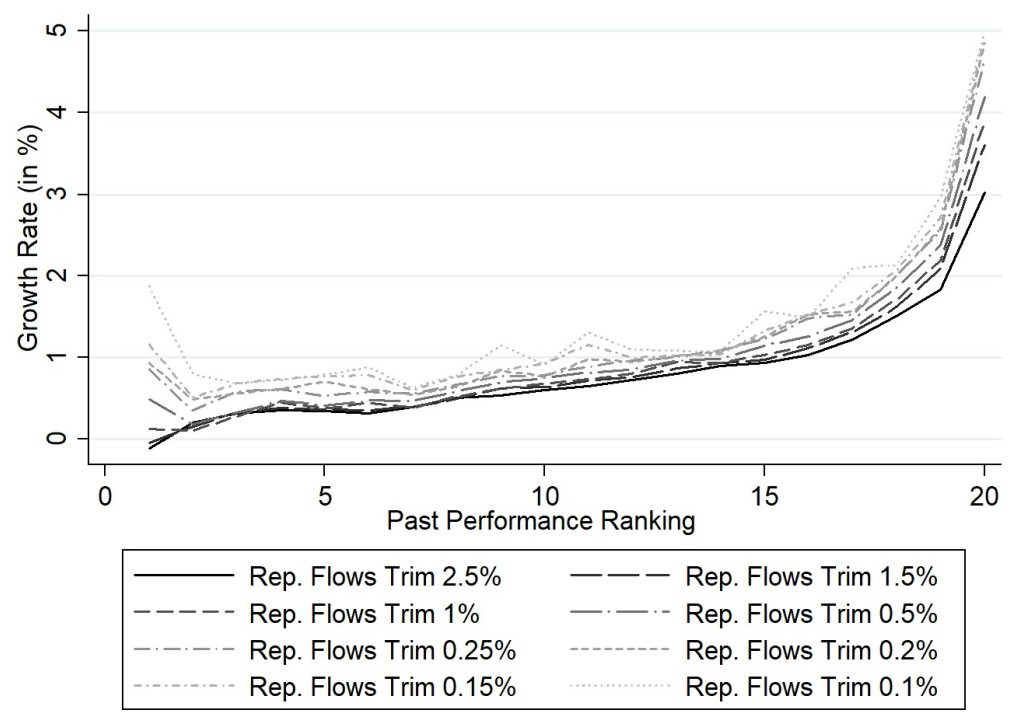

B: Winsorized Data

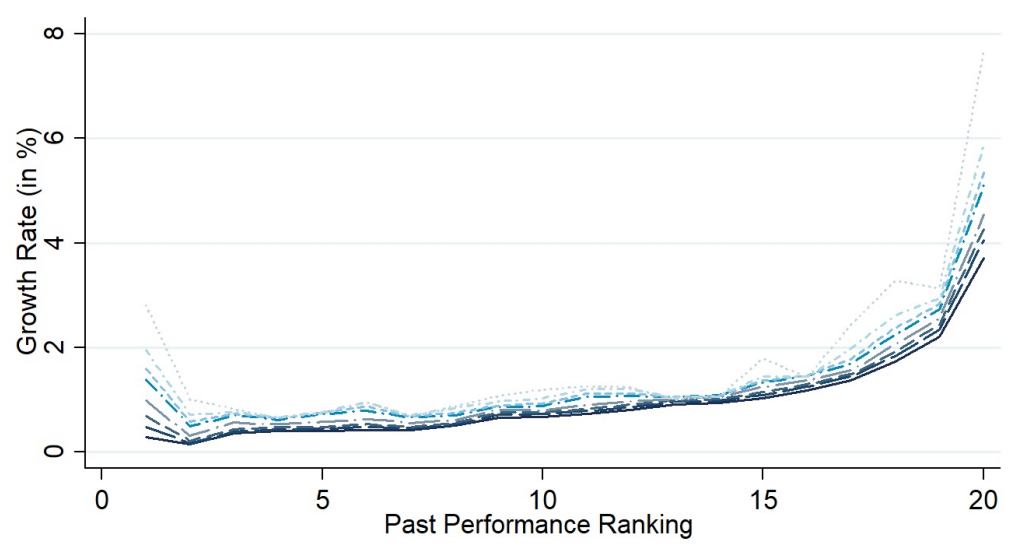

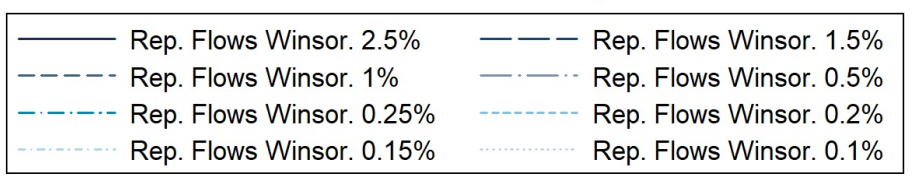

For each period from 1999 to 2014, funds are ordered within their respective investment objective (growth and income, aggressive growth, growth, equity-income, income, and small company), and ranked into twenty equal clusters based on their respective rolling annual returns. For each rank, we calculate the respective mean growth rate of the funds within that cluster. Growth rate is defined as the ratio of fund flows and total net assets, as follows: Flow $/ T N A_{t-1}$, where Flow is the fund flow reported to the SEC at time textitt. We apply eight different trimming or winsorizing quantiles $(0.1 \%, 0.15 \%, 0.2 \%, 0.25 \%, 0.5 \%, 1 \%, 1.5 \%$, and $2.5 \%)$ in order to treat outlying fund flows. This results in eight distinct samples. The upper graph plots a line for each sample showing the respective combination of mean growth rate and prior return ranking for trimming. The lower figure replicates this graph for winsorizing. 
Figure 3: Flow-Performance Relationship Using Trim and Winsorize at 1\%

A: Approximated Flows

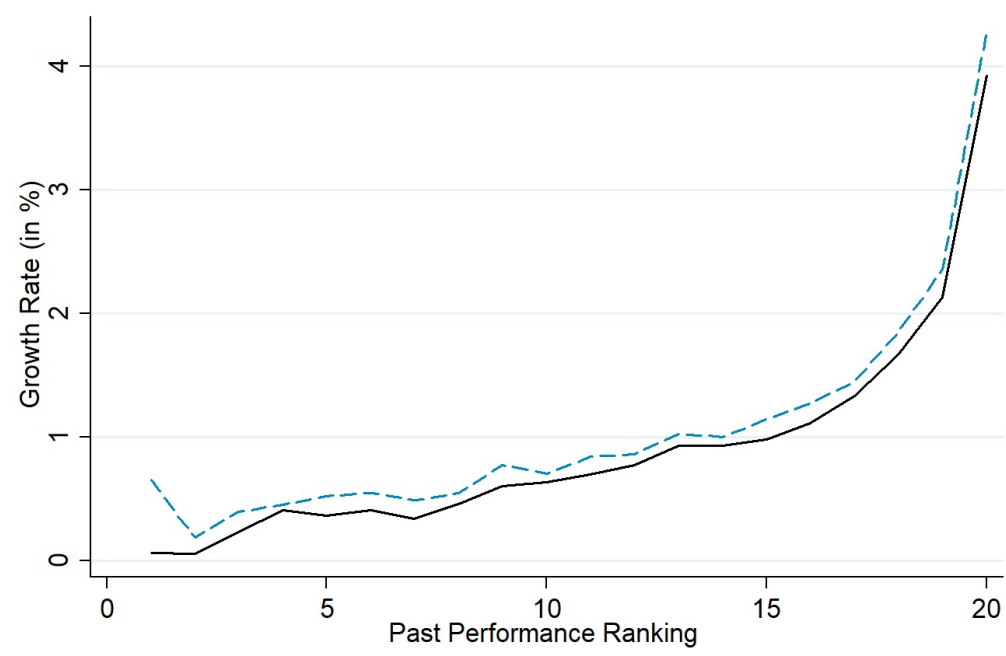

Approx. Flows Trim 1\% - - - - Approx. Flows Winsor 1\%

B: Reported Flows

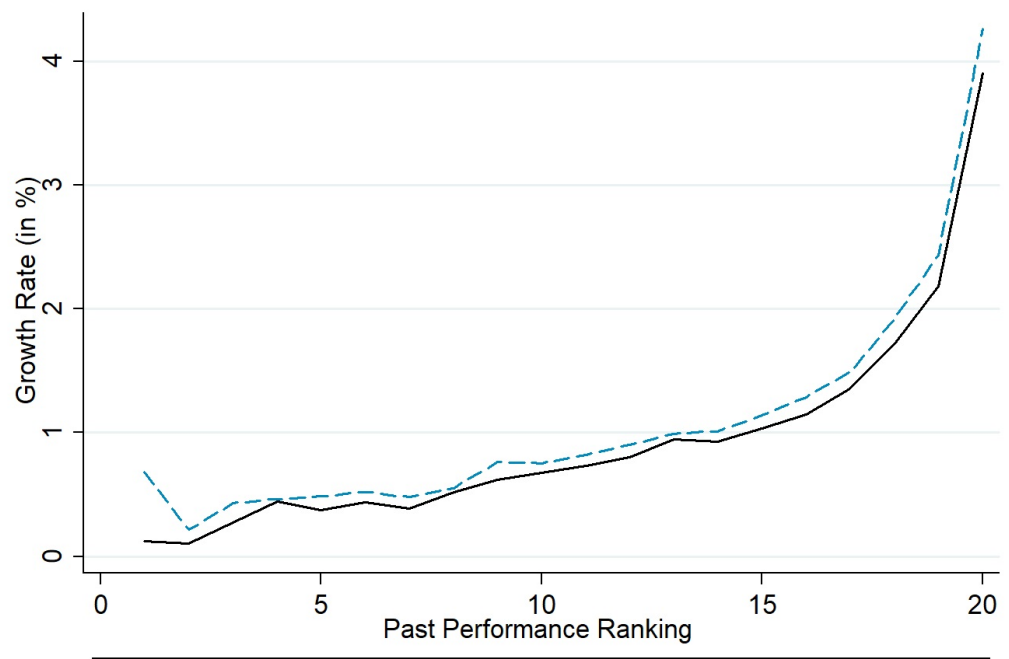

Reported Flows Trim 1\% $\quad-----$ Reported Flows Winsor 1\%

For each period from 1999 to 2014, funds are ordered within their respective investment objectives (growth and income, aggressive growth, growth, equity-income, income, and small company), and ranked into twenty equal clusters based on their respective rolling annual returns. For each rank, we calculate the respective mean growth rate of the funds within that cluster. We apply two different outlier treatment methodologies to either trim or winsorize at the $1 \%$ quantile, resulting in two distinct samples. We then plot a line for each sample showing the respective combination of mean growth rate and prior return ranking. In the upper panel, the growth rate is given by $\left(T N A_{t^{-}} T N A_{t-1}\left(1+R_{i, t-1}\right)\right) / T N A_{t-1}$, where $R_{i, t}$ is the fund's monthly return at time textitt. In the lower panel, the growth rate is defined as the ratio of fund flows and total net assets, defined as Flow $_{t} / T N A_{t-1}$, where Flow $w_{t}$ is the fund flow reported to the SEC at time textitt. 


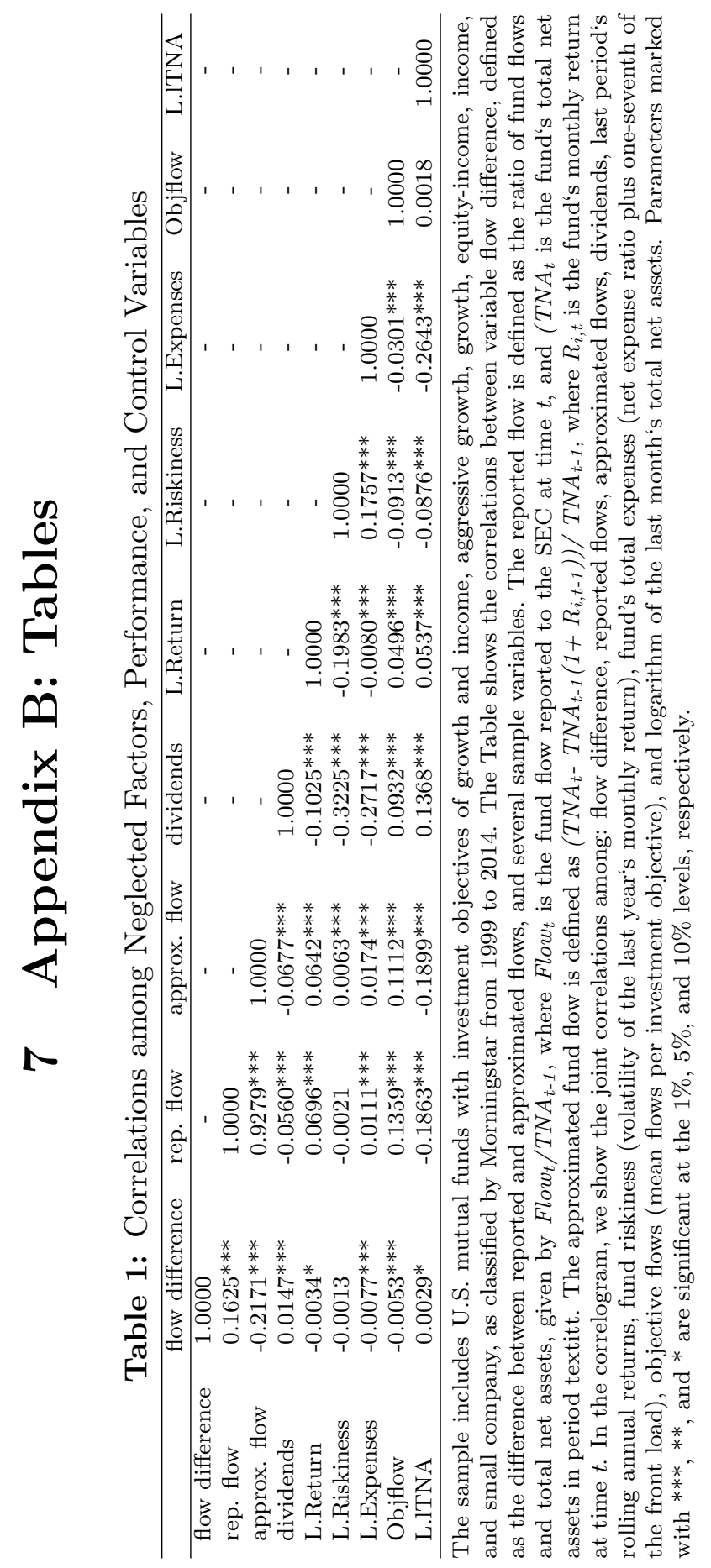




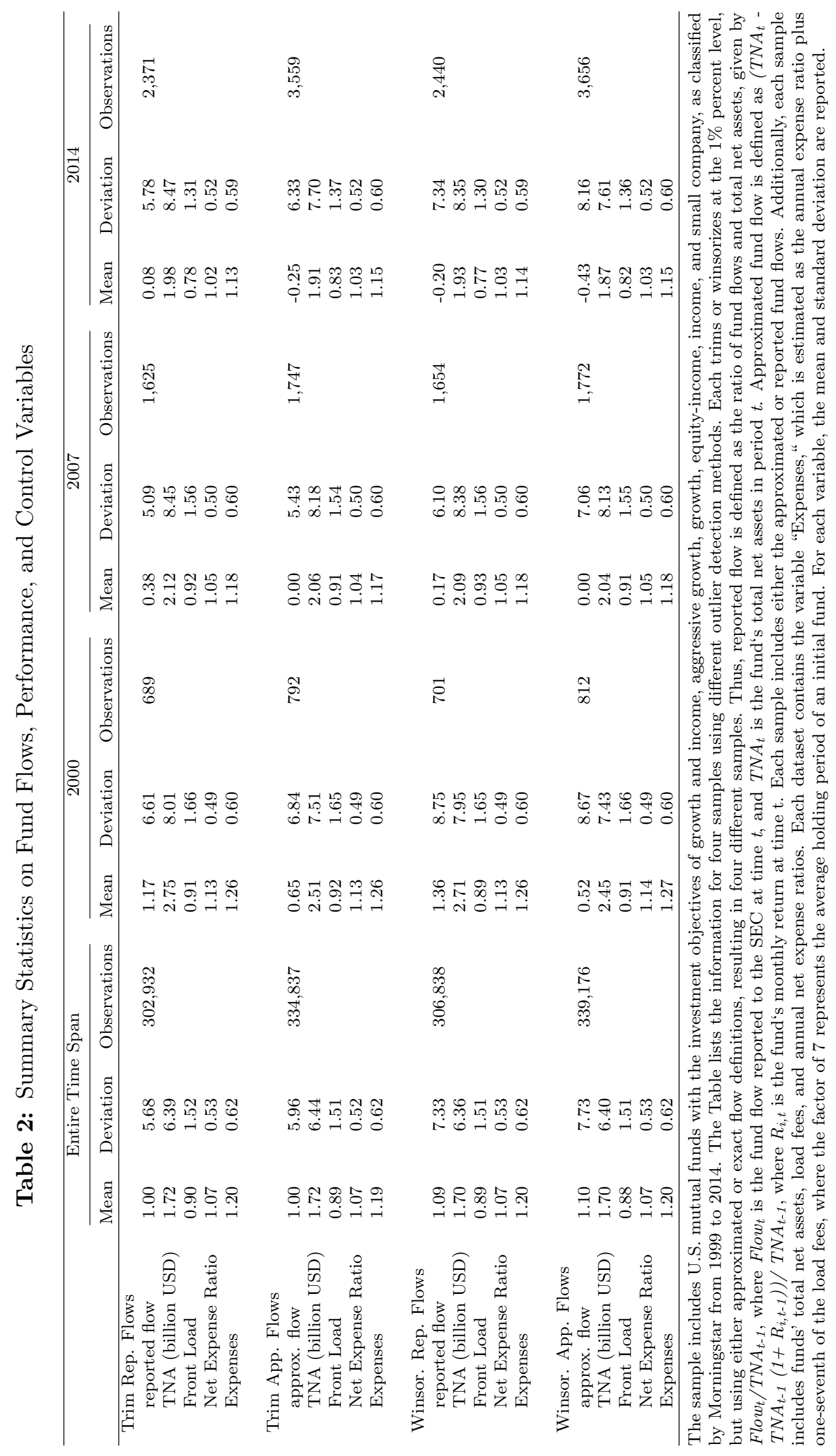


Table 3: Regression Results of the Fama-MacBeth Two-Step Procedure

\begin{tabular}{|c|c|c|c|c|c|c|c|c|}
\hline \multirow[b]{3}{*}{ VARIABLES } & \multicolumn{2}{|c|}{ Winsorize } & \multicolumn{2}{|c|}{ Trim } & \multicolumn{2}{|c|}{ Winsorize } & \multicolumn{2}{|c|}{ Trim } \\
\hline & Model (i) & Model (ii) & Model (iii) & Model (iv) & Model (viii) & Model (vii) & Model (vi) & Model (v) \\
\hline & Approx. & Reported & Approx. & Reported & Approx. & Reported & Approx. & Reported \\
\hline \multirow[t]{2}{*}{ L.lowReturn } & 0.919 & 0.992 & $1.613^{* * *}$ & $1.824^{* * *}$ & $1.699 * * *$ & $1.487^{* *}$ & $2.659 * * *$ & $2.234^{* * *}$ \\
\hline & $(0.773)$ & $(0.707)$ & $(0.554)$ & $(0.490)$ & $(0.571)$ & $(0.573)$ & $(0.258)$ & $(0.298)$ \\
\hline \multirow[t]{2}{*}{ L.midReturn } & $2.166^{* * *}$ & $2.201^{* * *}$ & $2.120 * * *$ & $2.138 * * *$ & $1.154 * * *$ & $0.962^{* * *}$ & $0.883^{* * *}$ & $0.804^{* * *}$ \\
\hline & $(0.136)$ & $(0.118)$ & $(0.113)$ & $(0.0999)$ & $(0.113)$ & $(0.0960)$ & $(0.0718)$ & $(0.0689)$ \\
\hline \multirow[t]{2}{*}{ L.highReturn } & $15.50 * * *$ & $16.25^{* * *}$ & $15.48 * * *$ & $15.47^{* * *}$ & $8.204 * * *$ & $6.741^{* * *}$ & $5.825 * * *$ & $4.756^{* * *}$ \\
\hline & $(0.914)$ & $(0.970)$ & $(0.741)$ & $(0.725)$ & $(0.718)$ & $(0.701)$ & $(0.448)$ & $(0.412)$ \\
\hline \multirow[t]{2}{*}{ L.Riskiness } & $0.0454^{*}$ & 0.00872 & 0.0315 & -0.00457 & 0.0332 & 0.0126 & $-0.0401^{* * *}$ & $-0.0442^{* * *}$ \\
\hline & $(0.0254)$ & $(0.0252)$ & $(0.0197)$ & $(0.0203)$ & $(0.0243)$ & $(0.0234)$ & $(0.0134)$ & $(0.0124)$ \\
\hline \multirow{2}{*}{ L.Expenses } & $-0.268^{* * *}$ & $-0.291 * * *$ & $-0.242^{* * *}$ & $-0.251 * * *$ & $-0.149 * * *$ & $-0.162^{* * *}$ & $-0.108^{* * *}$ & $-0.114^{* * *}$ \\
\hline & $(0.0375)$ & $(0.0370)$ & $(0.0293)$ & $(0.0299)$ & $(0.0314)$ & $(0.0297)$ & $(0.0208)$ & $(0.0211)$ \\
\hline \multirow[t]{2}{*}{ Objflow } & $0.532^{* * *}$ & $0.518^{* * *}$ & $0.674^{* * *}$ & $0.642^{* * *}$ & $0.327^{* * *}$ & $0.294^{* * *}$ & $0.204^{* * *}$ & $0.207^{* * *}$ \\
\hline & $(0.0270)$ & $(0.0312)$ & $(0.0303)$ & $(0.0338)$ & $(0.0248)$ & $(0.0296)$ & $(0.0224)$ & $(0.0237)$ \\
\hline \multirow[t]{2}{*}{ L. $\log (\mathrm{TNA})$} & $-0.528 * * *$ & $-0.502 * * *$ & $-0.390 * * *$ & $-0.377 * * *$ & $-0.309 * * *$ & $-0.258 * * *$ & $-0.142^{* * *}$ & $-0.130 * * *$ \\
\hline & $(0.0146)$ & $(0.0149)$ & $(0.00886)$ & $(0.0101)$ & $(0.00966)$ & $(0.0109)$ & $(0.00571)$ & $(0.00709)$ \\
\hline \multirow[t]{2}{*}{ Constant } & $9.187^{* * *}$ & $8.862^{* * *}$ & $6.305^{* * *}$ & $6.254^{* * *}$ & $4.852^{* * *}$ & $4.094^{* * *}$ & $1.955^{* * *}$ & $1.876^{* * *}$ \\
\hline & $(0.353)$ & $(0.367)$ & $(0.255)$ & $(0.270)$ & $(0.247)$ & $(0.261)$ & $(0.148)$ & $(0.175)$ \\
\hline \multirow[t]{2}{*}{ L.flow } & - & - & - & - & $0.101^{* * *}$ & $0.197 * * *$ & $0.258^{* * *}$ & $0.306^{* * *}$ \\
\hline & - & - & - & - & $(0.00757)$ & $(0.0128)$ & $(0.00755)$ & $(0.0119)$ \\
\hline \multirow[t]{2}{*}{ L2.flow } & - & - & - & - & $0.112^{* * *}$ & $0.121^{* * *}$ & $0.132^{* * *}$ & $0.125^{* * *}$ \\
\hline & - & - & - & - & $(0.00675)$ & $(0.0102)$ & $(0.00575)$ & $(0.00741)$ \\
\hline \multirow[t]{2}{*}{ L3.flow } & - & - & - & - & $0.0850^{* * *}$ & $0.0790 * * *$ & $0.0836^{* * *}$ & $0.0812^{* * *}$ \\
\hline & - & - & - & - & $(0.00631)$ & $(0.00804)$ & $(0.00487)$ & $(0.00620)$ \\
\hline \multirow[t]{2}{*}{ L4.flow } & - & - & - & - & $0.0494 * * *$ & $0.0543^{* * *}$ & $0.0526^{* * *}$ & $0.0414^{* * *}$ \\
\hline & - & - & - & - & $(0.00620)$ & $(0.0119)$ & $(0.00456)$ & $(0.0103)$ \\
\hline \multirow[t]{2}{*}{ L5.flow } & - & - & - & - & $0.0517^{* * *}$ & $0.0430^{* * *}$ & $0.0395 * * *$ & $0.0388^{* * *}$ \\
\hline & - & - & - & - & $(0.00606)$ & $(0.00781)$ & $(0.00457)$ & $(0.00566)$ \\
\hline \multirow[t]{2}{*}{ L6.flow } & - & - & - & - & $0.0438 * * *$ & $0.0406^{* * *}$ & $0.0330 * * *$ & $0.0378^{* * *}$ \\
\hline & - & - & - & - & $(0.00617)$ & $(0.00968)$ & $(0.00445)$ & $(0.00638)$ \\
\hline \multirow[t]{2}{*}{ L7.flow } & - & - & - & - & $0.0246^{* * *}$ & $0.0209^{* * *}$ & $0.0136^{* * *}$ & -0.00222 \\
\hline & - & - & - & - & $(0.00581)$ & $(0.00627)$ & $(0.00403)$ & $(0.0148)$ \\
\hline \multirow[t]{2}{*}{ L8.flow } & - & - & - & - & $0.0258^{* * *}$ & $0.0353^{* *}$ & $0.0276^{* * *}$ & $0.0280^{* * *}$ \\
\hline & - & - & - & - & $(0.00533)$ & $(0.0142)$ & $(0.00421)$ & $(0.00543)$ \\
\hline L9.flow & - & - & - & - & $0.0209 * * *$ & $0.0198^{* *}$ & $0.0139 * * *$ & $0.0234^{*}$ \\
\hline & - & - & - & - & $(0.00562)$ & $(0.00961)$ & $(0.00444)$ & $(0.0134)$ \\
\hline L10.flow & - & - & - & - & 0.00467 & 0.000111 & $0.0130^{* * *}$ & 0.0143 \\
\hline & - & - & - & - & $(0.00531)$ & $(0.0149)$ & $(0.00376)$ & $(0.0103)$ \\
\hline L11.flow & - & - & - & - & $0.0136^{* * *}$ & 0.00286 & $0.00765^{* *}$ & $0.0123^{*}$ \\
\hline & - & - & - & - & $(0.00460)$ & $(0.00992)$ & $(0.00346)$ & $(0.00634)$ \\
\hline L12.flow & - & - & - & - & $0.0206^{* * *}$ & $0.0227 * * *$ & $0.0169 * * *$ & 0.00997 \\
\hline & - & - & - & - & $(0.00398)$ & $(0.00793)$ & $(0.00324)$ & $(0.0100)$ \\
\hline Observations & 339,176 & 306,838 & 334,837 & 302,932 & 327,312 & 264,244 & 295,985 & 239,416 \\
\hline Number of groups & 179 & 179 & 179 & 179 & 179 & 179 & 179 & 179 \\
\hline $\mathrm{R}$-squared & 0.058 & 0.063 & 0.072 & 0.075 & 0.224 & 0.308 & 0.329 & 0.374 \\
\hline Adj. R-squared & 0.055 & 0.059 & 0.069 & 0.071 & 0.221 & 0.305 & 0.326 & 0.371 \\
\hline
\end{tabular}

This table shows Fama and MacBeth (Fama and MacBeth (1973)) regression results using a U.S. mutual fund sample with the investment objectives of growth and income, aggressive growth, growth, equity-income, income, and small company from 1999 to 2014. The table reports regression coefficient estimates using fund flows as the dependent variable. It lists the information for four samples using different fund flow definitions and outlier detection methods. Each trims or winsorizes at 1\%, but using either approximated or exact fund flow definitions, resulting in four distinct samples. The reported flow is thus defined as the ratio of fund flows and total net assets given by Flow $/ T N A_{t-1}$, where Flow $w_{t}$ is the fund flow reported to the SEC at time $t$, and $T N A_{t}$ is the fund's total net assets in period $t$. The approximated fund flow is defined as $\left(T N A_{t}-T N A_{t-1}\left(1+R_{t-1}\right)\right) / T N A_{t-1}$, where $R_{t}$ is the fund's monthly return at time $t$. 
Column (i) shows the results incorporating approximated fund flows that are winsorized at the $1 \%$ level. Column (ii) contains the regression results for the case of using fund flows as reported to the SEC instead of the approximated version. Columns (iii) and (iv) replicate the specifications in columns (i) and (ii), this time trimming instead of winsorizing the outliers. Columns (v) to (viii) replicate the analysis of the first four columns, this time controlling for fund flow persistence. The independent variables include fund $i$ 's relative performance measure to time $t$ to explain subsequent fund flows. In each time period, all funds within the same investment objective are then ranked according to their performance. This variable is called $\operatorname{Rank}_{i, t}$, and ranges from 0 to 1 . Next, the performance is separated into three performance percentiles, which allows us to model a potential non-linear relationship between fund flows and past performance: The bottom quantile is defined as: low return $n_{i, t-1}=\min \left(0.2, \operatorname{Rank}_{\mathrm{i}, \mathrm{t}-1}\right)$, the middle quantile is defined as: $\operatorname{mid}_{\text {return }}, \mathrm{t}-1=\min (0.6$, $\operatorname{Rank}_{\mathrm{i}, \mathrm{t}-1}$ - low return $\left.\mathrm{i}_{\mathrm{t}-\mathrm{t}-1}\right)$, and the high-performance quantile is defined as: high return $\mathrm{i}_{\mathrm{t}-\mathrm{t}-1}=\min \left(0.2, \operatorname{Rank}_{\mathrm{i}, \mathrm{t}-1}\right.$ - mid return $n_{\mathrm{i}, \mathrm{t}-1}$ - low return $\left.\mathrm{i}_{\mathrm{i}, \mathrm{t}-1}\right)$. We use rolling twelve-month returns as a measure of fund performance $\left(R_{i, t}\right)$. We also control for the volatility of fund $i$ 's monthly returns from the preceding year, the fund's past period total expenses (given by the annual expense ratio plus one-seventh of the load fees), the objective flows, defined as the growth rate of all funds in the same investment category, and the log of the fund's last month total net assets. Standard errors are in parentheses, and p-values are denoted by asterisks $\left({ }^{* * *} 0.01,{ }^{* *} 0.05,{ }^{*} 0.1\right)$. 